\title{
Nonperforming loans and competing rules of monetary policy: A statistical identification approach ${ }^{\text {th }}$
}

\author{
Emiliano Brancaccio ${ }^{\mathrm{a}, *}$, Andrea Califano ${ }^{\mathrm{b}}$, Milena Lopreite ${ }^{\mathrm{c}}$, Alessio Moneta ${ }^{\mathrm{c}}$ \\ a Dipartimento DEMM, Università degli Studi del Sannio Italy \\ ${ }^{\mathrm{b}}$ IUSS - Scuola Universitaria Superiore Pavia Italy \\ 'Institute of Economics - Scuola Superiore Sant'Anna, Pisa Italy
}

\section{A R T I C L E I N F O}

\section{Article history:}

Received 19 November 2019

Revised 13 January 2020

Accepted 7 February 2020

Available online 10 February 2020

\section{JEL classification:}

C32

C52

E52

E58

Keywords:

Taylor rule

Solvency rule

Nonperforming loans

Causal inference

Structural vector autoregressive models

\begin{abstract}
A B S T R A C T
We assess to what extent decisions taken by the Federal Reserve in setting interest rates can be interpreted in the light of monetary policy rules that are either built on standard objectives of output and price stabilization or based on alternative objectives of financial stability and regulation of the solvency conditions in the economic system. This goal is pursued through a comparison between the "Taylor rule" in its "original" and "augmented" versions, and an alternative "Solvency rule". We use nonperforming loans as a proxy for the conditions of financial stability and solvency in the system. The empirical investigation is carried out following a structural vector autoregressive approach that exploits a statistical identification procedure. In this way, we are able to identify the causal structure among variables without imposing theoretical restrictions on the model. Our empirical findings provide very limited and incomplete support for the Taylor rule in its various forms while give comprehensive evidence in favor of the alternative Solvency rule.
\end{abstract}

(c) 2020 Elsevier B.V. All rights reserved.

\section{Introduction}

The pillars of macroeconomic theory have been violently shaken by the so called great recession: an "earthquake" - as it was defined - able to tear apart many of the certainties permeating the discipline (Christiano, 2017). This applies to the specific field of monetary policy as well. As a matter of fact, the efficacy of central banks' intervention, their fundamental goals, even the general role they are deemed to have in the economic system have been object of an intense debate. This new ferment of ideas is also noticeable in the discussion on the so-called "rules" of behavior of central banks. In the present work we intend to contribute to this debate by analysing if and to what extents the decisions taken during three decades by the U.S. Federal Reserve in setting the interest rates can be effectively interpreted in the light of those

\footnotetext{
We are grateful to two anonymous referees of this journal for their useful comments. The usual disclaimers apply.

* Corresponding author.

E-mail addresses: emiliano.brancaccio@unisannio.it (E. Brancaccio), andrea.califano@iusspavia.it (A. Califano),m.lopreite@santannapisa.it (M. Lopreite), a.moneta@santannapisa.it (A. Moneta).
}

monetary policy rules which are built on the standard objectives of output and price stabilization, or rather should be examined in the light of the scopes of financial stability and regulation of the solvency conditions in the economic system.

This analysis is conducted through a comparison between the "Taylor rule" in its "original" (Taylor, 1993) and "augmented" (see Käfer, 2014, and references therein) versions, and an alternative view called "Solvency rule" (Brancaccio and Fontana, 2013; 2016; Brancaccio and Suppa, 2018).

We empirically assess the theoretical causal relations implied by these rules on the basis of a structural vector autoregressive approach which adopts a specific statistical identification procedure and avoids, as much as possible, assumptions derived from economic theory. By adopting this procedure we look at the United States in order to verify whether the actual monetary policy of the Federal Reserve during the period 1988-2016 can be more easily interpreted in the light of the causal relations implied by the "Taylor rule" or is more in line with the alternative nexus formalized in the "Solvency rule". Our analysis is therefore of a positive rather than a normative nature. In other words, neither do we intend to suggest what the central bank should do or are we interested in what the central bank claims to do (see for instance Romer and 
Romer, 1989). Our research is limited only to verifying which monetary policy rule is more consistent with the causal relationships among variables which emerge from the available data, regardless of the more or less explicit purposes of the monetary authority.

In this work, we introduce a new variable rarely covered in the literature on policy "rules" (for a partial exception, see Zilberman and Tayler, 2014): nonperforming loans, which we will consider either as a macroprudential indicator in the "augmented" version of the Taylor rule or as proxy of the solvency conditions in the "Solvency rule". With respect to the method to identify the causal relationships among the variables of interest we use structural vector autoregressive (SVAR) models. Structural models allow to analyse causal relationships in more details with respect of reduced-form models, but usually they have the disadvantage of relying on a priori assumptions. In this paper, however, we apply a statistical procedure for identification, which is based on independent component analysis (Moneta et al., 2013) and eschews, as much as possible, economic-theoretic assumptions. This allows us to empirically identify, under the assumptions of non-Gaussianity and independence of structural shocks, the contemporaneous causal structure, the structural impulse response functions, and the forecast variance decomposition. This data-driven technique is, in our opinion, particularly appropriate for comparative exercises, where the aim is to analyse different relationships between variables that arise from alternative theoretical interpretations of monetary policy.

The rest of the paper is organized as follows. Section 2 briefly describes some features of the main debate on monetary policy goals and related "rules" and compare them with a possible alternative view based on the concept of "Solvency rule". Section 3 proposes a simple comparative scheme of the competing interpretations of monetary policy and the related causal relationships based either on the "Taylor rule" or on the "solvency rule". Section 4 clarifies the way in which this work analyses the causality between the variables at play. Section 5 describes the data we use in our empirical analysis. Section 6 presents the structural VAR framework and the identification strategy. Section 7 shows the results. Section 8 concludes.

\section{Current debates on financial stability in the taylor rule and a possible alternative view}

A relevant problem in the current debate on monetary policy concerns whether or not it is necessary to assign to central banks the task of contributing to the financial stability of the economic system. The multiple sides of this issue have been tackled from many different viewpoints (Akerlof et al., 2014; Blanchard et al., 2010; Blot et al., 2015; Borio, 2008; 2014; Claessens and Habermeier, 2013; IMF, 2015, see). From the analytic point of view, the debate has focused on the need to assess if the monetary policy "rules" usually applied to analyse central banks' behaviour are also able to pursue the goal of financial stability. The evaluation was primarily directed towards the renowned "Taylor rule" (Taylor, 1993; 1999). Such rule describes the way in which the central bank can set the rate of interest according to deviation of inflation and output from their respective "equilibrium" levels, in order to pursue the minimization of such gaps in the business cycle: the lower output and inflation with respect to the equilibrium levels, the lower will have to be the interest rate needed to push them up, and vice versa. In the view of the scholar who invented it, the Taylor rule implicitly targets the goal of financial stability as well: sticking to the rule would guarantee a balanced financial development, whereas deviations from the rule may set up the premises for the outbreak of a financial crisis. In short, according to Taylor, his "rule" allows the central bank to preserve the financial stability not simply by virtue of the possibility to move GDP and inflation up or down, but because it allows to stabilize their values around precise equilibrium levels, which ultimately correspond to the "natural" equilibrium determined by the "fundamentals" of preferences, technology and scarce resources that are typical of neoclassical theory. On the basis of this interpretation, it has been argued that the credit boom which anticipated the recession started in 2008 would have been caused by the decision taken by the Federal Reserve to set the interest rate well below the path suggested by the Taylor rule (Taylor, 2009a; 2009b). According to this view, then, not only would the Taylor rule be able to ensure the stability of inflation and output, but also financial stability. This interpretation, however, has found wide opposition, even among the appraisers of the rule. For instance, some of them claim that an "augmented" version of the Taylor rule should have to be applied, if one is to analyse past financial crises and in order to prevent them to happen again. Such augmented rules, besides targeting output and price stability, would require a direct control of credit dynamics or other macroprudential indicators, to avoid the occurrence of episodes of financial instability (Agénor et al., 2013; Akerlof et al., 2014; Beau et al., 2012; Bhar and Malliaris, 2016; Blanchard et al., 2010; Gambacorta and Signoretti, 2014; Krug, 2015; Mattesini and Becchetti, 2009; Ozkan and Unsal, 2014; Smets, 2014; Verona et al., 2014), (see Tamborini, 2010, for a different point of view). For example, this would mean that facing an excessive amount of credit or an excessive rise in equity prices, the monetary authority would be led to increase the interest rate to "cool down" the system and avert financial turbulence. In a nutshell, this is a description of what goes under the name of "leaning against the wind" monetary policy, which has gained a growing interest in recent years. As we shall see, in this paper we consider nonperforming loans as a possible macroprudential indicator within the "augmented Taylor rule".

The debate on the relation between the Taylor rule and the scope of financial stability is still open, and many scholars and policy makers are involved (see Akerlof et al., 2014; Blanchard et al., 2010; Käfer, 2014). It is worth mentioning that though they advocate different sets of criteria considered to be relevant to preserve financial stability, the scholars involved in the discussion usually do not make objections on a double causal relation which is typical of the Taylor rule and of the other conventional rules of monetary policy: in fact, they firstly accept that the central bank is deemed to set the interest rate as a function of the deviations of the GDP from its "equilibrium" level and of inflation from its "target" level; secondly, they accept that in setting the interest rate in this way, the central bank is then thought to be always effective in affecting those gaps. The latter relation, however, has not always fared well when it comes to empirical testing: it is actually not certain that the manipulation of the interest rate is effective in managing the performance of GDP and inflation. In the last few years this causal relation has been put into question most notably by the issue of the zero lower bound. Yet the many doubts on the validity of this relation are in fact widely known since long time and inspire critiques of a more general character. Outstanding within these critiques the idea that the influence of the interest rate on investment, hence more generally on the aggregate demand, often turns out to be weak, delayed, and, most fundamentally, uncertain (Arestis and Sawyer, 2008; Bernanke and Gertler, 1995; Blinder and Maccini, 1991; Chirinko, 1993; Kriesler and Lavoie, 2007; Orphanides, 2001; Primiceri, 2005; Shapiro et al., 1986; Sharpe and Suarez, 2015).

The seldom satisfactory empirical evidence of a causal relation from the policy interest rate to aggregate demand, GDP and inflation yields some implications in the debate on the validity of the "Taylor rule" and related interpretations of monetary policy. It also provides elements to support interpretations of the role of central banks quite different from those suggested by the Taylor rule. In 
particular, in recent years a renewed interest has been devoted to the old "Radcliffe Report" (Committee on the working of the monetary system, 1959; for recent contributions on this subject, see Aikman et al. 2016).

This highly articulated and in some aspects contradictory report has been analysed and developed in various directions. Here we intend to focus on two aspects often neglected in the literature but highlighted by Kaldor (1960, 1985). First, the Radcliffe Report not merely did question the old monetarist theory of a stable relation between money and nominal income, but also raised strong doubts on the ability of the interest rates and other monetary policy variables to govern aggregate demand, GDP and inflation. Second, on the contrary, the Radcliffe Report claimed that interest rate maneuvers and other monetary policy actions can have significant repercussions on the stability and solvency of financial institutions. One of the possible ways to interpret these indications is as follows. The prior role of central banks does not lie in taking charge of the management of the business cycle and of inflation, as this management may be in fact out of their actual control. The main task assigned to monetary authorities would concern instead the capacity of monetary policy to affect the sustainability of the financial positions in the economic system. Given the levels of income, inflation, the stock of debt accumulated by households, firms, banks and public institutions, their financial positions would result on average either more sustainable or less so, depending on the actions taken by the central bank on the interest rates and other monetary variables. For instance, when income and inflation are low with respect to due reimbursements of debt, private and public debtors in the system will be in a fragile position and low level of the interest rates will be needed, so as to make refinancing possible and avoid a situation of insolvency. On the contrary, if income and inflation are high compared to reimbursements of debt, debtors positions will be safer and they will be able to deal with a tighter interest rate policy. Thus, according to this vision, the prior function of central banks consists in preserving the stability of the financial setting, and more broadly in regulating the conflicting relationships between creditors and debtors and then managing the solvency conditions within the economic system.

The just described interpretation suggests an idea of monetary policy in many ways discretionary and in any case quite complex, which could hardly be reduced to a mere mathematical "rule" (Dow, 2017). Nonetheless, some basic aspects that can be traced back to this vision have recently been summarized in a formalization which goes under the name of "Solvency rule" (Brancaccio and Fontana, 2013; 2016; Brancaccio and Suppa, 2018). When compared with the "Taylor rule" and its variants, the "Solvency rule" shows one formal similarity and several substantial differences. On the one hand, the "Solvency rule" does not rule out the standard behavioural causal relation according to which the central bank sets the interest rate as a function of the GDP and the inflation rate: the lower the GDP and the inflation, the lower the interest rate set by the central bank, and vice versa. On the other hand, among the determinants of the interest rate, the "Solvency rule" also includes other variables which are meaningful in the description of the solvency conditions in the economic system, and most notably the nonperforming loans: the higher the level of such loans, the lower will be the rate of interest set by the monetary authority. In addition, the "Solvency rule" does not depend on the relevance of the causal relation which foresees the interest rate to affect GDP and inflation. Rather, the "Solvency rule" suggests another causal relation, according to which the interest rate set by the central bank deploys its influence on those variables representing the solvency conditions in the economic system: low interest rates should favour the drainage of nonperforming loans.

In short, with respect to the standard "Taylor rule", the "Solvency rule" does not need to assume that the central banker is always able to contribute to the control of the business cycle and of inflation. Furthermore, while the "augmented" version of the "Taylor rule" implies the monetary authority to adopt a "leaning against the wind" behaviour in order to prevent a financial boom to set on, the "Solvency rule" describes a central bank which intervenes in the opposite direction, paying attention to the already existing financial positions with the goal of guaranteeing their solvency. The interpretations described so far imply alternative views on the actual role assumed by central banks, relying on alternative sets of causal relations between the variables at the core of the deployment of monetary policy. If we stick to the "Taylor rule", the central bank pursues the goal of output and price stability, and this implicitly guarantees financial stability as well. According to the "augmented" version of the "Taylor rule", it is necessary to introduce further macroprudential variables among the determinants of the rate of interest in order for the central bank to target both GDP and price stability on the one hand and financial stability on the other. For the "Solvency rule" instead, rather than meeting the target of output and price stability, the central bank can affect the financial positions of the economic units in the system by regulating their solvency.

\section{Alternative rules of monetary policy: A comparative scheme}

We present now a simplified comparative scheme which aims at describing in an immediate way the causal relations suggested by the two competing interpretations of monetary policy described before. A discussion on their respective theoretical foundations, then, is beyond the scope of this work. The only basic theoretical difference that must be kept in mind here is that the concept of "equilibrium" that characterizes the "Taylor rule" is different from that which distinguishes the "Solvency rule". In particular, as we said, the "equilibrium" values of GDP, interest rate, inflation and nonperforming loans that are in the "Taylor rule" refer to a situation of full employment which is typical of the standard neoclassical growth and distribution models, possibly amended by the presence of asymmetries and market imperfections. On the contrary, in the Solvency rule the relationships between the above variables are completely different: the "equilibrium" values referred to can be simply considered as "targets" of policy authorities, which may also correspond to situations of high unemployment caused by lack of effective demand and independent of asymmetries or market imperfections (for an in-depth analysis, see Brancaccio and Fontana (2013)). After this specification, we can describe a simple scheme whose ambition is to compare the essential theoretical nuclei of the alternative interpretations of monetary policy examined. As we shall see, this scheme can be thought as a sort of "stereogram": depending on the different hypotheses on the exogenous variables or parameters, the same system of equations can describe the variety of causal relations the different monetary policy rules considered are grounded (on the origins and possible application of this comparative approach, see Dobb (1975); Dutt (1990); Hahn and Matthews (1964); Brancaccio (2010); Brancaccio and Califano (2018); see also Blanchard and Brancaccio (2019)).

The variables considered in this exercise are the following: $i_{t}$, $\pi_{t}, y_{t}$ and $N P L_{t}$ represent, respectively, the current values of the interest rate, inflation, production, and the amount of nonperforming loans; $i_{t}-\pi_{t}$ gives the current real interest rate and $\pi_{t-1}$ is the inflation in the previous period; $r^{*}, \pi^{*}, y^{*}$ and $N P L^{*}$ represent 'equilibrium' levels or 'policy targets'; finally, $\alpha, \beta, \gamma, \epsilon, \omega, \sigma, \rho$, $z$ are given parameters. The competing alternative interpretations of monetary policy described so far can be both contained by a unique system of equations:

$i_{t}=r^{*}+\pi_{t}+\alpha\left(\pi_{t}-\pi^{*}\right)+\beta\left(y_{t}-y^{*}\right)+\gamma\left(N P L_{t}-N P L^{*}\right)$ 


$$
\begin{aligned}
& N P L_{t}=N P L^{*}+\epsilon\left[\left(i_{t}-\pi_{t}-y_{t}\right)-\left(r^{*}-y^{*}\right)\right] \\
& y_{t}=y^{*}+\sigma-\omega\left(i_{t}-\pi_{t}\right) \\
& \pi_{t}=\pi_{t-1}+z+\rho\left(y_{t}-y^{*}\right)
\end{aligned}
$$

Eq. 1 can be representative of both a "Taylor rule" and a "Solvency rule". Within this equation, nonperforming loans can be considered as a macroprudential variable capturing financial stability in the "augmented" version of the "Taylor rule" or as a proxy for the solvency condition of the economic system in the "Solvency rule". Eq. 2 is based on the hypothesis that the level of nonperforming loans can be expressed as a function of the difference between the current real interest rate and the equilibrium' real rate, and of the difference between current production and the production of 'equilibrium': we can assume, in this sense, that the higher the levels of production and inflation with respect to the interest rates, the greater will be the nominal income of the debtors with respect to the nominal value of the cost of their debts, and therefore the lower will be the amount of nonperforming loans, and vice versa. Eq. 3 describes the performance of production compared to its 'equilibrium' value as a function of an autonomous component of aggregate demand and of the current real interest rate. Eq. 4 expresses the current inflation rate depending on a cost component and on the deviations of output form its 'equilibrium' value. Given the parameters and $\pi_{t-1}$ from the previous period, $i_{t}, \pi_{t}, y_{t}$ and $N P L_{t}$ are the unknowns. In all cases, $\alpha, \beta, \epsilon, \sigma, z$ have positive values while $\gamma$ can change its sign.

Assuming $\omega$ and $\rho$ to be positive, the system describes the causal relations typical of the Taylor rule, either in its original version or in the augmented one, depending on the value assigned to $\gamma$ (respectively null or positive). In the case of the standard Taylor rule, Eqs. 1, 3, 4 determine the unknown $i_{t}, y_{t}, \pi_{t}$ simultaneously, and then Eq. 2 determines $N P L_{t}$ as a residual. When we look at the augmented Taylor rule, the four equations determine simultaneusly the four unknowns. If we assume instead that $\omega$ and $\rho$ are null (or negligible) and that $\gamma$ is negative, the system describes the causal relations at the basis of the 'Solvency rule': in this case, Eq. 3 determines $y_{t}$, Eq. 4 determines $\pi_{t}$ and then 1 and 2 determine simultaneusly $i_{t}$ and $N P L_{t}$. It is clear that the causal relationships suggested by the different "rules" are completely different.

Some of the simplifying hypotheses of the just described comparative scheme are inspired by a teaching model suggested by Taylor (2000). Obviously, the same scheme can be made more complex by introducing micro and macro determinants of the different visions examined, new hypotheses on the expectations, different temporal lags for the variables, and so on. In any case the fundamental relations suggested by the alternative views would not change. Then, we can test the empirical reliability of these different causal relations. The following paragraphs will be devoted to this objective.

\section{A data-driven analysis of causality}

Preliminary to the empirical analysis, some clarifying remarks are needed on the meaning that we attach, within the scope of this work, to the concept of causal relation and to the method we will apply in order to test it empirically.

In recent years many ideas on causation developed in the philosophy of science and machine learning community have been applied to econometrics, where directed graphs are used to represent causal relations. According to Pearl (2009), a functional causal model is a system of equations in which each equation represents a distinct and autonomous causal mechanism; this means that it is possible to modify a single mechanism (and the corresponding equation) without changing the other causal relationships in the system. In this case, the intervention consists in assigning a new value to a variable, substituting this new value in all the equations in which the variable occurs but leaving the structure and the coefficients of the equations unaltered. Pearl's assumption is that the variables that change their value under this intervention will do so only due to the effect of the considered variable. Finally, the causal influence can be measured through a linear regression model in which by manipulating the independent variables we can analyse the changes of the dependent variable. In this way not only can we capture the correlations between variables but we can also measure the 'marginal effect', which indicates how much $y$ changes when $x$ increases and in which direction. The crucial question in this framework is, not surprisingly, how it is possible to learn about causal relationships (constituting functional causal models) starting from the data and under general assumptions that only minimally depend on economic theory. Pearl (2009) and Spirtes et al. (2000) propose to use graphical causal models not only for the sake of representation but also of inference, under some principles that connect causal structures to probability distributions. This line of research has been recently expanded by the application of independent component analysis (ICA) (Comon, 1994). In particular, under general assumptions on the data generating process (existence of independent shocks affecting the system, non-Gaussianity, recursiveness, and linearity), Shimizu et al. (2006) propose an ICA-based search algorithm that learn a causal structure from non-experimental data. Our method to assess the causal implications of the different monetary policy rules described in the previous section proceeds consistently with this strand of literature. We start from the estimation of a Vector Autoregressive (VAR) model, that is an econometric framework able to cope with a set of time series data, and we address the identification problem by applying ICA. The structural VAR model is recovered following a statistical method that allow to estimate both the contemporaneous causal structure and the the dynamic causal effects among the variables.

There is an established tradition in applying structural VAR model to study monetary policy decisions and their effects on macroeconomic variables (Bernanke and Mihov (1998); Christiano et al. (1999); Sims (1986); Uhlig (2005)), trying to disentangle both the contemporaneous and dynamic causal effects. Structural VAR models have been applied to identify monetary policy rules by Choi and Wen (2010), Sousa (2010), and Kociecki et al. (2012). These studies, however, use identification strategies that strongly hinges on a priori assumptions.

Our goal in the present work is to compare the different interpretations of monetary policy and the corresponding causal relations as described so far by assessing their relevance through a data-driven empirical analysis, in which identification is achieved not by imposing restrictions derived from economic theory, but rather through general assumptions on the statistical and structural properties of the data generating process.

Following Capasso and Moneta (2016); Gourieroux et al. (2017); Hyvärinen and Oja (2000); Lanne et al. (2017); Moneta et al. (2011, 2013), our study is focused on the ICA-based empirical identification of SVAR models on the basis of the following general assumptions: (i) the shocks that affect the system are mutually independent and non-Gaussian; (ii) the contemporaneous causal structure is recursive.

\section{Data}

We use quarterly US data, covering the period from 1988:Q1 to 2016:Q4. The sample span is determined by the data availability. Our variables of interest are the following: the federal funds rate (FFR); the real GDP (2009 dollars), in logarithms (GDP); the 

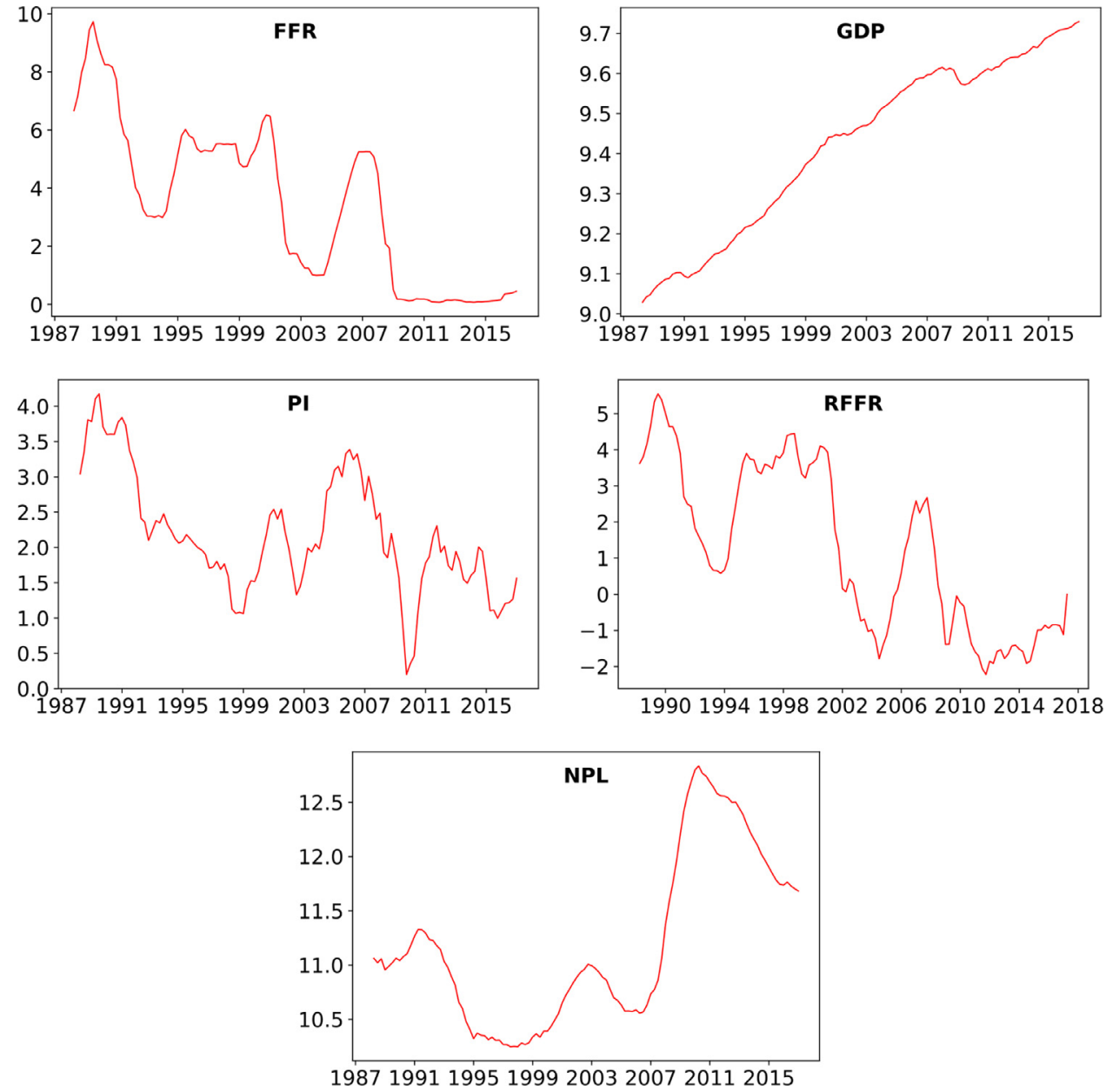

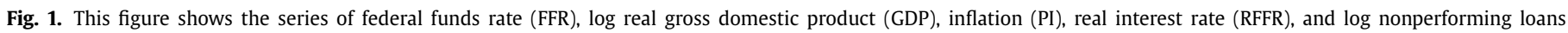
(NPL).

price inflation, calculated as the annual rate of change of the implicit price deflator GDP $(P I)$; the real federal funds rate, i.e. FFR minus PI $(R F F R)^{1}$; the total amount of nonperforming loans for commercial banks, in logarithms (NPL). The data are drawn from the Federal Reserve Economic Data (FRED) database. ${ }^{2}$ All the series taken from this database are quarterly data, except for the federal funds rate that is monthly. To transform the federal funds rate in quarterly observation we simply take the arithmetic mean over three months. Fig. 1 plot the series of the data. From eye inspection already, the series look non-stationary. As shown in the subsections below, the non stationarity of all series is confirmed by a battery of unit root tests: the Dickey Fuller (ADF), the Phillips Perron (PP), and the Kwiatkowski Phillips Schmidt Shin (KPSS) tests, in all cases at $5 \%$ level of significance.

\section{Estimation and identification method}

Vector autoregressive models were introduced by Sims (1980) to describe macroeconomic dynamics by treating all variables as potentially endogenous. The point of departure in VAR analysis is the specification and estimation of a reduced form

\footnotetext{
1 We thus follow the Fisher's equation similarly to King et al. (1991).

2 In particular, we downloaded from the FRED website (https://fred.stlouisfed.org) the following codes: FEDFUNDS (source: Board of Governors of the Federal Reserve System), GDPC1 and GDPDEF (source: U.S. Bureau of Economic Analysis), USNP (source: Federal Financial Institutions Examination Council).
}

model:

$\mathbf{y}_{t}=\boldsymbol{\mu}_{t}+\mathbf{A}_{1} \mathbf{y}_{t-1}+\ldots+\mathbf{A}_{p} \mathbf{y}_{t-p}+\mathbf{u}_{t}$,

where $\mathbf{y}_{t}=\left(y_{1 t}, \ldots, y_{k t}\right)^{\prime}$ is a vector of $k$ time series variables, the $\mathbf{A}_{i}(i=1, \ldots, p)$ are $(k \times k)$ coefficient matrices, and $\mathbf{u}_{t}=\left(u_{1 t}, \ldots\right.$, $\left.u_{k t}\right)^{\prime}$ is a $k$-dimensional zero mean white noise process with covariance matrix $E\left(\mathbf{u}_{t} \mathbf{u}_{t}^{\prime}\right)=\boldsymbol{\Sigma}_{\mathbf{u}}$. The vector $\boldsymbol{\mu}_{t}$ is a deterministic part, which in many cases is simply equal to a vector of constants.

Eq. (5) is an approximate description of the unobserved data generating process (DGP), whose adequacy can be checked with the typical criteria of model selection and model checking, such as, for example, sequential testing procedure, Akaike or Schwarz's information criteria for selecting the VAR order (i.e. $p$ ), and tests for residual autocorrelation (see Lütkepohl, 2005). An important feature of the reduced form model (5) is that it omits the fact that there might be mutual influences among the contemporaneous variables (within the period of observation) among $y_{1 t}, \ldots, y_{k t}$. This omission is done in order to keep the variables on the right hand side of the equation as pre-determined and hence getting consistent estimation of the coefficients through simple linear regression. But, precisely because of this omission, the coefficients being estimated cannot be interpreted as genuine causal influences.

Structural VAR analysis attempts to identify structural, i.e. causally meaningful, relations among the variables. The structural VAR model lets the (unobserved) coefficients that describe the contemporaneous causal influence to appear in the equation:

$\boldsymbol{\Gamma}_{0} \mathbf{y}_{t}=\boldsymbol{v}_{t}+\boldsymbol{\Gamma}_{1} \mathbf{y}_{t-1}+\ldots+\boldsymbol{\Gamma}_{p} \mathbf{y}_{t-p}+\boldsymbol{\varepsilon}_{t}$ 
Table 1

Unit root tests.

\begin{tabular}{|c|c|c|c|c|c|}
\hline Variables & Lags & ADF test (test statistic) & KPSS test (test statistic) ${ }^{b}$ & PP test (test statistic) & Results \\
\hline GDP d & 2 & -1.45 & 0.85 & -0.74 & $\mathrm{I}(1)$ \\
\hline NPL ${ }^{a, c}$ & 5 & -1.65 & 1.06 & -1.07 & $\mathrm{I}(1)$ \\
\hline $\mathrm{PI}{ }^{\mathrm{a}, \mathrm{c}}$ & 5 & -3.01 & 0.15 & -2.47 & $\mathrm{I}(1)$ \\
\hline RFFR $^{\mathrm{d}}$ & 2 & -2.73 & 0.19 & -2.11 & $\mathrm{I}(1)$ \\
\hline
\end{tabular}

Notes: ${ }^{a, c}$ The critical value (ADF, PP statistic test) for PI and NPL at the $5 \%$ level of significance is equal to -2.89 and at the $1 \%$ level of significance is equal to -3.49 . $^{\text {b }}$ The critical value of KPSS statistic test for PI is equal to 0.14 at the $5 \%$ level of significance and it is equal to 0.21 at the $1 \%$ level of significance. The critical value for NPL is equal to 0.46 at the $5 \%$ level of significance and it is equal to 0.73 at the $1 \%$ level of significance. ${ }^{d}$ The critical value (ADF, PP statistic test) for the Real GDP and RFFR is equal to -3.44 at the $5 \%$ level of significance and it is equal to -4.04 at the $1 \%$ level of significance. ${ }^{\mathrm{b}}$ The critical value of KPSS statistic test for the Real GDP and RFFR is equal to 0.15 at the $5 \%$ level of significance and it is equal to 0.21 at the $1 \%$ level of significance.

Table 2

Johansen test.

\begin{tabular}{llllll}
\hline Variables & Lags & $\mathrm{H}_{0}$ & $\lambda$ stat trace & $\lambda$ stat $\max$ & Results \\
\hline GDP, NPL, PI, RFFR & 2 & $\mathrm{r}=0$ & $56.54(0.0053)$ & $31.83(0.0106)$ & Cointegrated \\
& & $\mathrm{r}=1$ & $24.71(0.18)$ & $13.48(0.42)$ & \\
\hline
\end{tabular}

Notes: The p-values are shown in parentheses.

where $\boldsymbol{\Gamma}_{0}$ is a $(k \times k)$ matrix reflecting the instantaneous relations, and the $\boldsymbol{\Gamma}_{i}(i=1, \ldots, p)$ are the coefficient matrices of the lagged structural relations, reflecting causal influences present in the DGP. Again, the vector $\boldsymbol{\varepsilon}_{t}=\left(\varepsilon_{1 t}, \ldots, \varepsilon_{k t}\right)^{\prime}$ is a $k$-dimensional zero mean white noise process with covariance matrix $E\left(\boldsymbol{\varepsilon}_{t} \boldsymbol{\varepsilon}_{t}^{\prime}\right)=\boldsymbol{\Sigma}_{\boldsymbol{\varepsilon}}$, and $\boldsymbol{v}_{t}$ is the deterministic or constant part. In standard structural VAR analysis $\boldsymbol{\Sigma}_{\boldsymbol{\varepsilon}}$ is assumed to be diagonal, i.e. correlations among $\varepsilon_{i t}$ (over $i=1, \ldots, k$ ) are zero. This is also equivalent to stating that the $\varepsilon_{i t}$ are orthogonal (conditional on the $\varepsilon_{i t}$ having a mean of zero). Besides assuming orthogonality and uncorrelatedness, we assume that $\varepsilon_{i t}$ is independent of $\varepsilon_{j t}$ for each $i, j=1, \ldots, k(i \neq j)$. The independence assumption is consistent with the interpretation of the elements of $\boldsymbol{\varepsilon}_{t}$ as structural shocks, i.e. exogenous processes that affect each variable of the system at each time with the important feature that each term influences each variable in its own independent way. While in a setting with normally distributed error terms the distinction between independence and uncorrelatedness does not matter, in a non-Gaussian setting this further specification is crucial (see Hyvärinen and Oja, 2000).

It is also assumed that the diagonal elements of $\boldsymbol{\Gamma}_{0}$ are equal to one (or that the system can always be rescaled in order to have ones in the main diagonal of $\boldsymbol{\Gamma}_{0}$ ). Let $\mathbf{B}=\mathbf{I}-\boldsymbol{\Gamma}_{0}$. Thus Eq. (6) can be rewritten as

$\mathbf{y}_{t}=\boldsymbol{v}_{t}+\mathbf{B} \mathbf{y}_{t}+\boldsymbol{\Gamma}_{1} \mathbf{y}_{t-1}+\ldots+\boldsymbol{\Gamma}_{p} \mathbf{y}_{t-p}+\boldsymbol{\varepsilon}_{t}$

Eq. (7) cannot be directly estimated by linear regression because not all the variables on the right hand side are predetermined or exogenous: some elements of $\mathbf{y}_{t}$ may instantaneously (i.e. within the period of observation) cause other elements of $\mathbf{y}_{t}$, without knowing which one. The relationship between the reduced form (see Eq. 5) and the structural model (see Eq. 6 or 7) is evident by pre-multiplying equation (6) or (7) by $\boldsymbol{\Gamma}_{0}^{-1}$ or $(\mathbf{I}-\mathbf{B})^{-1}$. We have that $\boldsymbol{\Gamma}_{0}^{-1} \boldsymbol{\Gamma}_{i}=\mathbf{A}_{i}(i=1, \ldots, p), \quad \boldsymbol{\Gamma}_{0}^{-1} \boldsymbol{v}_{t}=\boldsymbol{\mu}_{t}$ and $\boldsymbol{\Gamma}_{0}^{-1} \boldsymbol{\varepsilon}_{t}=\mathbf{u}_{t}$. The problem of identification consists in the fact that, having estimated the reduced form model we cannot directly recover the structural form model, because there are more parameters in Eq. (6) than in equation (5).

Structural VAR analysis is focused on imposing restrictions on $\boldsymbol{\Gamma}_{0}$ so that it can be retrieved from the data. The matrices $\boldsymbol{\Gamma}_{i}$ $(i=1, \ldots, p)$, in turn, can be recovered from $\boldsymbol{\Gamma}_{0}$ joint with the $\mathbf{A}_{i}$ which are obtained from the estimation of Eq. (5). The restrictions on $\boldsymbol{\Gamma}_{0}$ are usually derived from theoretical or institutional knowledge, or placed on the basis of considerations about the long-run effects or signs of the shocks. In this paper instead, we apply an identification method focused on inferring the contemporaneous causal structure on the basis of the study of the reduced-form residuals. We adopt here the approach based on independent component analysis proposed by Moneta et al. (2013). Since this approach has been designed for non-Gaussian variables, in case of departure from non-normality we also check the robustness of the results under different approaches, in particular the search method based on graphical causal models (see Moneta et al., 2013).

\section{Results}

We estimate two different SVAR models. In a first model, that we call the real interest rate model, the vector $\mathbf{y}_{t}$ (see Eqs. 6 and 7) consists of the following variables: RFFR, PI, GDP, NPL (as defined in the previous section). A second model, that we call the nominal interest rate model, is identical to the first one, except that RFFR is replaced with FFR. The difference between the two models relates to the possibility or not of making explicit the monetary policy rule in terms of interest rate net of inflation directly. In the literature it is possible to find both formulations in a wide range of analytical contexts (see for instance King et al. (1991)). Anyhow, as we shall see, from our tests it turns out that the estimation results of the two models do not make significant differences in terms of our answers to the research questions. Thus we present detailed and numerical results for the real interest rate model only, but we will flag the similarities and the few differences with respect to the results of the nominal interest rate model.

Table 1 shows that the four series (RFFR, PI, GDP, NPL) turn out to be non-stationary, and in particular integrated of order one (I(1)). Table 2 shows the results of the Johansen cointegration test (see Johansen, 1991), which suggests to not reject the presence of

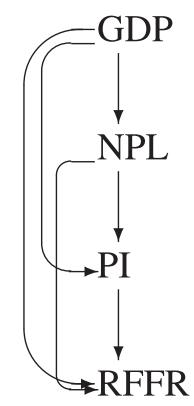

Fig. 2. Contemporaneous causal structure, output of the LiNGAM algorithm. 


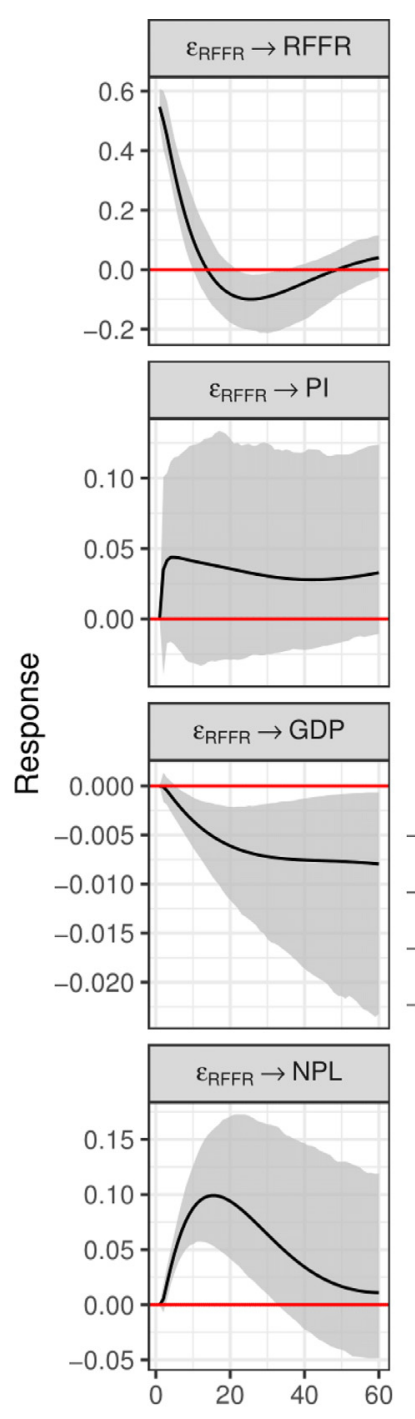

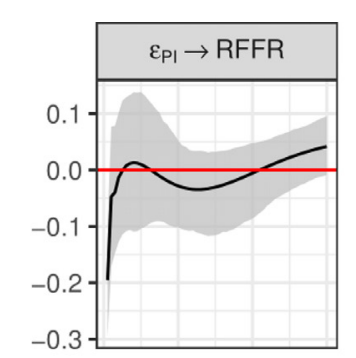
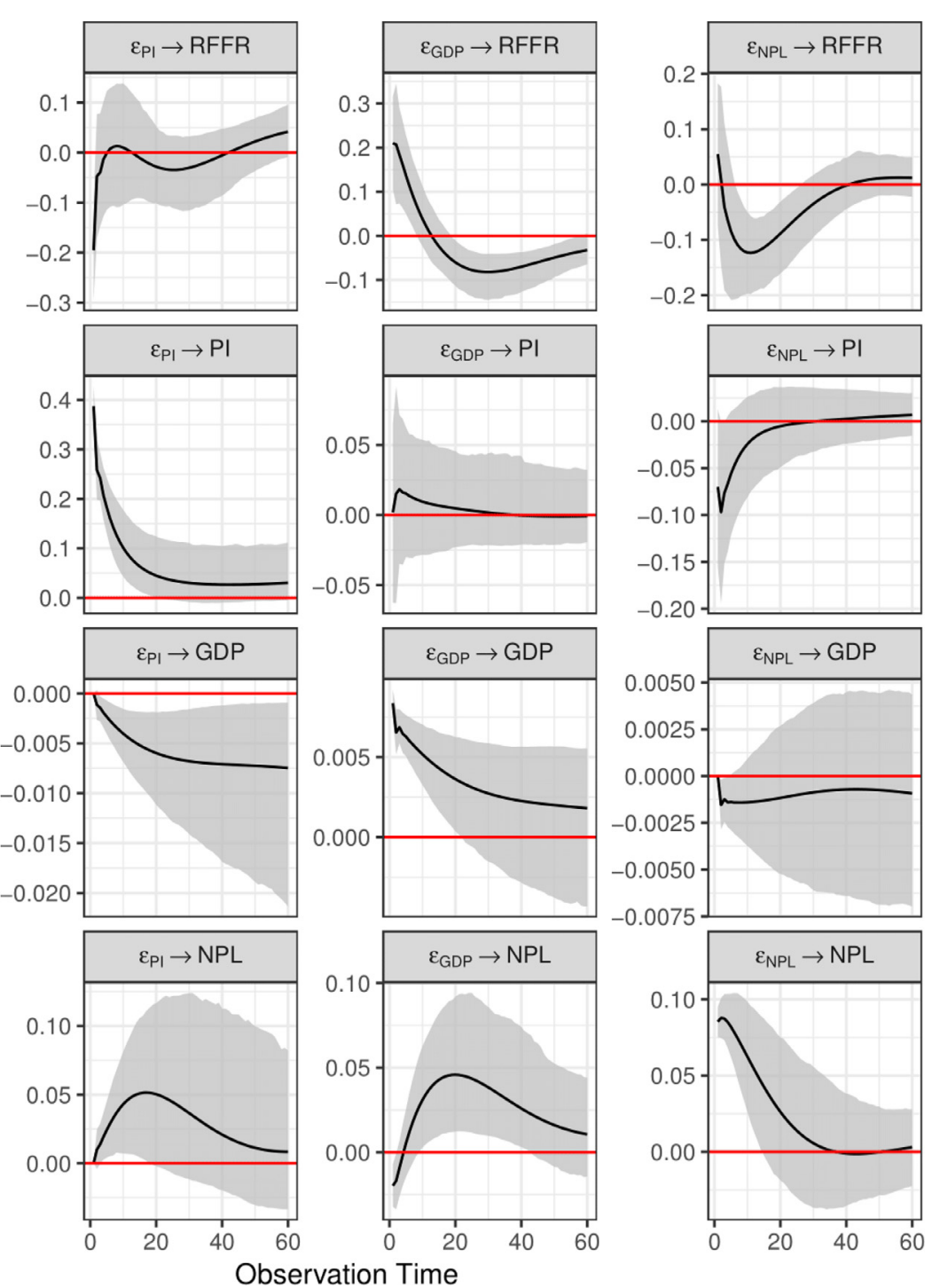

Fig. 3. Impulse response functions with $90 \%$ confidence bounds of real interest rate, inflation, real GDP and nonperforming loans.

one cointegrating relationship among the variables. With regard to the nominal interest rate model, also FFR turns out to be $I(1)$ and, using Johansen test, we also get one cointegrating relationship.

In order to exploit the non-Gaussian feature of the data and maintain the possibility of estimating the model with least absolute deviation (LAD), which is more robust to extreme events (characteristics of the recent economic crisis), we estimate the model in levels. The use of the LAD estimator was also proposed by Moneta et al. (2013) in a non-Gaussian SVAR framework. We select two lags under the Bayesian (BIC) and the Hannan-Quinn (HQC) information criterion for both models.

We identify the matrix B of Eq. (7), which represents the causal structure among the contemporaneous variables, using the LiNGAM algorithm (Shimizu et al., 2006). In a first step this algorithm applies ICA (in particular the FastICA algorithm by Hyvarinen, 1999) to the reduced-form residuals $\mathbf{u}_{t}$ (see Eq. 5), finding a set of independent shocks, whose order and correspondence with the variables are left underdetermined. ICA can be applied only if at most one of the reduced-form residuals turn out to be Gaussian. Applying normality test (Shapiro-Francia), normality is not rejected only for the residual corresponding to inflation $(P I)$ in both the real and nominal interest rate model.

In a second step, under the assumption of recursiveness, the algorithm matches shocks and variables, producing both the B and the vector $\boldsymbol{\varepsilon}_{t}$ (see Eq. 7). The assumption of recursiveness means that the contemporaneous causal structure does not display feedback loops (cycles). In other words, it can be represented with a directed causal graph. Assuming that there is a recursive causal structure means also that in principle the system is identifiable using a Cholesky decomposition of the reduced-form residuals, under an appropriate causal order. ${ }^{3}$.

Thus our method is also compatible with the traditional SVAR identification scheme (Sims, 1980), with the crucial difference that the causal order is not imposed a priori, but inferred from the data (for more details on the application of the LiNGAM algorithm to the SVAR framework see Moneta et al., 2013). ${ }^{4}$

\footnotetext{
${ }^{3}$ When the components are Gaussian uncorrelatedness implies independence and we can estimate the mixing matrix only up to an arbitrary orthogonal matrix. For non-Gaussian variables, on the other hand,uncorrelatedness and independence are not equivalent. The ICA estimation is performed by finding uncorrelated components that maximize non-Gaussianity (Hyvärinen and Oja, 2000). Moreover, combining the assumption of acyclicity with non Gaussianity (i.e LINGAM) we obtain a perfect identifiability of the model (Shimizu et al., 2006)

${ }^{4}$ Note that the recursiveness assumption allows the matching between variables and shocks because this assumption implies a certain number of zero in the matrices $\mathbf{B}$ and $\boldsymbol{\Gamma}_{0}^{-1}$. This means that one shock is affecting $k$ variables, another shock is affecting $k-1$ variables, and so on. The LiNGAM algorithm exploits this fact to find the exact matching (Shimizu et al., 2006).
} 
Variance Decomposition of RFFR

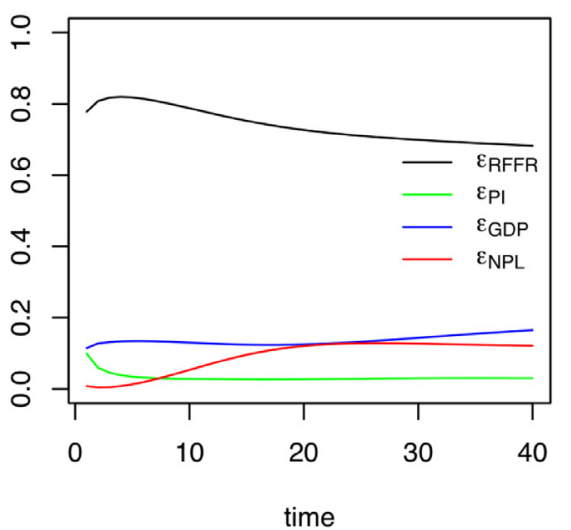

Variance Decomposition of GDP

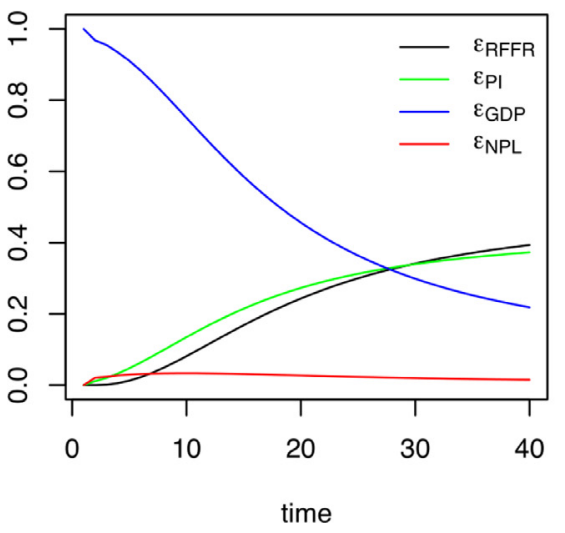

Variance Decomposition of PI

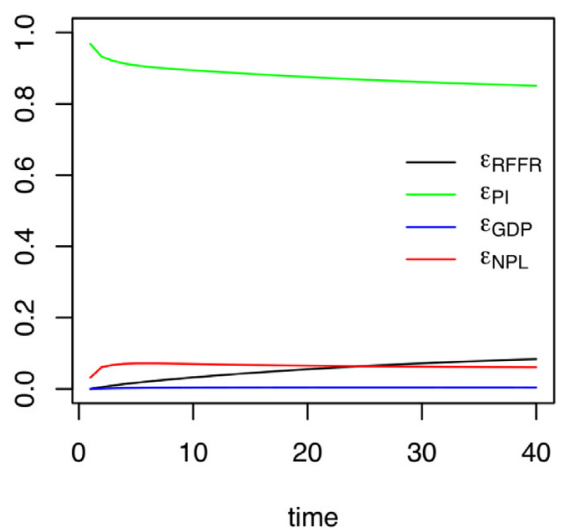

Variance Decomposition of NPL

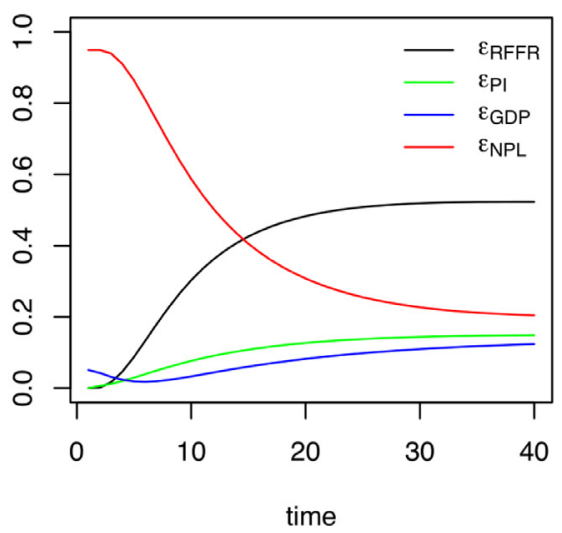

Fig. 4. Forecast variance decomposition of real interest rate, inflation, real GDP and nonperforming loans.

Fig. 2 shows the directed acyclic graph of the contemporaneous causal structure derived from our estimation of matrix $B$ and suggests that the real interest rate, which we can consider here the main instrument of monetary policy, responds to GDP, nonperforming loans, and inflation.

We repeat the same analysis with the nominal interest rate model and we obtain a causal graph identical to the one represented in Fig. 2, except that RFFR is replaced with FFR.

The results shown in Fig. 2 are in line with both the theoretical approaches we discussed above, namely the Taylor rule and the Solvency rule. However, an analysis considering only the contemporaneous relationships among the variables might not be sufficient to capture the effects of monetary policy interventions.

The dynamic causal effects are therefore studied through the analysis of the impulse response functions, which show the (one standard deviation) effect of a hypothetical intervention of one variable, keeping the others constant, in a longer period. We thus estimate the impulse response functions and the forecast variance decomposition on the basis of the contemporaneous causal order that results from LiNGAM, as represented in Fig. 2, namely $<G D P$, NPL, PI, RFFR $>$. The impulse response functions are displayed in Fig. 3. We show the dynamic effects until sixty quarters (i.e. 15 years). The plots show also the region delimited by $90 \%$ confidence intervals, obtained through a bootstrap procedure with 1000 iterations.

The first column of Fig. 3 displays the effects of the (one standard deviation) RFFR (real federal funds rate) shock. The contemporaneous impact of RFFR on itself shows that the standard deviation of the structural RFFR shock is about 0.55. The RFFR shock displays an effect on inflation (PI) that is not significant over time (second plot of the column). This suggest that an exogenous intervention on RFFR is not able to produce significant changes in inflation. The effect of the RFFR shock on GDP is not significant in the first three quarters and then becomes slightly negative and significant in the subsequent quarters (third plot of the column). Thus RFFR has limited effects on output (around $0.5 \%$ in the long run), but, in comparison, the effect of the RFFR shock on NPL is much greater (fourth plot of the column). Indeed an RFFR shock yields (positively) until 10\% changes in NPL after 20 periods. This suggests the presence of a strong causal relationship from an intervention on RFFR to NPL in the short and medium run.

The second column of Fig. 3 (second row) displays the effects of the (one standard deviation) PI (inflation) shock. The contemporaneous impact of PI on itself shows that the standard deviation of the structural PI shock is about 0.4. The effect of the PI shock on RFFR is not significant over time (first plot of the column). The effects of PI on GDP is negative and on NPL are positive, but not significant in the long run.

The third column of Fig. 3 (third row) displays the effects of the structural GDP shock, whose standard deviation is about 0.008 . As regards the effect of RFFR to GDP shock, it appears to be mainly concentrated in the short run: a shock on GDP has a positive and significant contemporaneous effect on RFFR, and this effect remains significant for about ten periods becoming ambiguous and insignificant later on (see first row, third column plot). The response of inflation to the GDP shock is not significant 
(second row, same column), while the response of NPL to GDP is ambiguous and short lived: negative in the first two quarters, positive after 10 quarters and not significant in the long run (fourth row, same column).

The fourth column of Fig. 3 (fourth row) displays the effects of the (one standard deviation) NPL (nonperforming loans) shock. The contemporaneous impact of NPL on itself shows that the standard deviation of the structural NPL shock is about 0.9. In response to an NPL shock, the RFFR decreases between 5 and 10 quarters, confirming the role played by the solvency condition of firms in monetary authorities' decisions (first plot in the fourth column).The effects of the NPL shock on inflation and GDP turn out not to be significant with few exceptions in the first periods.

These results are strongly confirmed in the impulse response functions in which nominal interest rate model (FFR) is used instead of RFFR.

The results of forecast variance decomposition functions, shown in Fig. 4, are in line with the impulse response functions and confirm that NPL and GDP are the fluctuations dominant source of RFFR (see first plot in the first row of Fig. 4). We also find a significant influence of RFFR on NPL (see last plot in the last row of Fig. 4). Finally, we observe a modest contribution of RFFR to the variance of real GDP (see first plot in the last row of Fig. 4) and a scarce contribution of PI to RFFR's variance (see first plot in the first row of Fig. 4). Very similar results are found in the nominal interest rate model.

We also inquired how robust the contemporaneous causal structure inferred from LiNGAM, from which structural impulse response functions and forecast error variance decomposition also depend, is under resampling. Thus, using a wild bootstrap procedure (1000 iterations), we checked how many times the LiNGAM algorithm was producing the contemporaneous causal structure displayed in Fig. 2), namely <GDP, NPL, PI, RFFR > . It turned out that $83 \%$ of the time the same structure was produced under resampling and $15 \%$ of the time the output was a slightly different structure, namely < GDP, NPL, RFFR, PI > . This means that in the contemporaneous causal order GDP and NPL (in this order) are ranked before the other two variables (PI and RFFR) $98 \%$ per cent of the time. We conclude that the main causal findings of the paper are therefore satisfactorily robust and the model is well identified.

\section{Conclusions}

This paper proposes a statistical identification approach to assess the reliability of the 'Taylor rule' and the so-called 'Solvency rule' for a description of U.S. monetary policy in the period 1988-2016. On the basis of our analysis, it is possible to draw the following empirical results.

First, the contemporaneous causal structure which has been identified (and is consistent across different specifications) suggests that the monetary policy instrument - nominal or real federal funds rate - responds in the same period to changes of all the variables considered: that is, not only real GDP and inflation but also nonperforming loans.

Second, a temporary rise in real GDP tends to be followed by a temporary increase of nominal or real funds rate.

Third, the manner in which changes in the nominal or real federal funds rate affect GDP over time is not significant in the first year and significant after one year. Moreover, the response of inflation to the federal funds rate is always not significant.

Fourth, we identify a positive and significant causal relation from changes in the federal funds rate to immediately subsequent changes in nonperforming loans. Furthermore, after a change in the nominal or real interest rate, an impact of the same sign on nonperforming loans remains substantially relevant and statistically significant for more than 30 periods (about 7 years).
The empirical analysis seems to confirm the conventional idea that the monetary authority sets the interest rate taking into consideration the values of inflation and GDP; it suggests nonetheless that central bank's decisions over the rate of interests are also influenced by nonperforming loans. At the same time, the results put into question a crucial part of the Taylor rule in all of its specifications: although the interest rate may significantly affect GDP after one year, it is not able to affect inflation in any time lapse considered. Furthermore, as we found out that the interest rate affects the amount of nonperforming loans with a positive influence, our analysis seems not to be consistent with the "leaning against the wind" policy which is implicit in the "augmented Taylor rule", whereas it seems to provide support to the alternative monetary policy interpretation suggested by the "Solvency rule". To sum up, the results of the present work point to a general interpretation of the behaviour of the central bank which questions the view implicit in the Taylor rule and its augmented variants,while could be compatible with an alternative view inspired by Kaldor's interpretation of the Radcliffe Report and synthesized in the "Solvency rule" (Brancaccio and Fontana, 2013; 2016; Brancaccio and Suppa, 2018). In fact, empirical evidence seems to be in line with the idea that the main role of the central bank, rather than being primarily concerned with the prior task of output and price stabilization, concerns a regulation of the financial positions of the economic units, making interest rates more or less sustainable for debtors in order to manage the stability and the solvency conditions in the economic system. This result suggests a very different view of monetary policy from that proposed by the advocates of "neutrality". The action of central banks, apparently, seems to be "anti-neutral", not only with regard to the usual management of the business cycle but also and above all in relation to the solvency conditions in the economic system (for a possible related view, see also Cardinale and Scazzieri, 2016 p. 50 n. 10). This evidence offers new elements to support the thesis that through the regulation of solvency, monetary policy can affect the pace of bankruptcies, liquidations and therefore also acquisitions and mergers between capitals, i.e. it can intervene on the rhythm of the so-called "centralization of capital" (Brancaccio et al., 2019).

\section{CRediT authorship contribution statement}

Emiliano Brancaccio: Conceptualization, Supervision, Methodology, Validation, Formal analysis, Investigation, Writing - original draft, Writing - review \& editing. Andrea Califano: Methodology, Validation, Formal analysis, Investigation, Writing - original draft, Resources, Data curation. Milena Lopreite: Methodology, Software, Validation, Formal analysis, Investigation, Writing - original draft, Writing - review \& editing, Resources, Data curation. Alessio Moneta: Supervision, Methodology, Software, Validation, Formal analysis, Investigation, Writing - original draft, Writing - review \& editing, Funding acquisition.

\section{References}

Agénor, P., Alper, K., Silva, L.P., et al., 2013. Capital regulation, monetary policy and financial stability. Int. J. Cent. Bank. 9 (3), 193-238.

Aikman, D., Bush, O., Taylor, A.M., 2016. Monetary versus macroprudential policies: causal impacts of interest rates and credit controls in the era of the UK radcliffe report. Natl. Bur. Econ. Res.

Akerlof, G., Blanchard, O., Romer, D., Stiglitz, J., 2014. What have we learned?: Macroeconomic policy after the crisis. IMF Working Paper.

Arestis, P., Sawyer, M., 2008. New consensus macroeconomics and inflation targeting: keynesian critique. Economia e Sociedade 17 (SPE), 629-653.

Beau, D., Clerc, L., Mojon, B., 2012. Macro-prudential policy and the conduct of monetary policy. Banque de France WP.

Bernanke, B.S., Gertler, M., 1995. Inside the black box: the credit channel of monetary policy transmission. J. Econ. Perspect. 9 (4), 27-48.

Bernanke, B.S., Mihov, I., 1998. Measuring monetary policy. Q. J. Econ. 113 (3), 869-902. 
Bhar, R., Malliaris, A., 2016. Asset price momentum and monetary policy: time-varying parameter estimation of taylor rules. Appl. Econ. 48 (55), 5329-5339.

Blanchard, O., Brancaccio, E., 2019. Crisis and revolution in economic theory and policy: a debate. review of political economy. Rev. Polit. Econ. 31 (2), 271-287.

Blanchard, O., Dell'Ariccia, G., Mauro, P., 2010. Rethinking macroeconomic policy. IMF Work. Pap. 2 (12).

Blinder, A., Maccini, L.J., 1991. Taking stock: a critical assessment of recent research on inventories. J. Econ. Perspect. 5 (1), 73-96.

Blot, C., Creel, J., Hubert, P., Labondance, F., Saraceno, F., 2015. Assessing the link between price and financial stability. J. Financ. Stab. 16, 71-88.

Borio, C., 2008. The Search for the Elusive twin goals of monetary and financial stability. In: Jonung, L., Walkner, C., Watson, M. (Eds.), Building the financial foundations of the euro. Routledge, London.

Borio, C., 2014. Monetary policy and financial stability: What role in prevention and recovery? Bank for International Settlements (BIS) Working Paper No 440.

Brancaccio, E., 2010. On the impossibility of reducing the surplus approach to a neoclassical special case: a criticism of hahn in a solowian context. Rev. Polit. Econ. 22 (3), 405-418.

Brancaccio, E., Califano, A., 2018. Anti-Blanchard Macroeconomics. A Comparative Approach. Edward Elgar.

Brancaccio, E., Fontana, G., 2013. 'Solvency rule' versus 'taylor rule': an alternative interpretation of the relation between monetary policy and the economic crisis. Cambridge J. Econ. 37 (1), 17-33.

Brancaccio, E., Fontana, G., 2016. 'Solvency rule' and capital centralisation in a monetary union. Cambridge J. Econ. 404 (4), 1055-1075.

Brancaccio, E., Giammetti, R., Lopreite, M., Puliga, M., 2019. Monetary policy, crisis and capital centralization in corporate ownership and control networks: a b-var analysis. Struct. Change Econ. Dyn. 51 (12), 55-66.

Brancaccio, E., Suppa, D., 2018. The "solvency rule" of the central banker in a monetary scheme of reproduction. Bull. Polit. Econ. 1 (2), 77-98.

Capasso, M., Moneta, A. 2016. Macroeconomic responses to an independent monetary policy shock: a (more) agnostic identification procedure. LEM working paper series No.2016/36,Sant'Anna School of Advanced Studies Laboratory of Economics and Management (LEM), Pisa, Italy.

Cardinale, I., Scazzieri, R., 2016. Structural liquidity: the money-industry nexus. Struct. Change Econ. Dyn. 39, 46-53.

Chirinko, R.S., 1993. Business fixed investment spending: modeling strategies, empirical results, and policy implications. J. Econ. Lit. 31 (4), 1875-1911.

Choi, W. G., Wen, Y., 2010. Dissecting Taylor rules in a structural VAR. International Monetary Fund working paper No.10/20

Christiano, L.J., 2017. The great recession: a macroeconomic earthquake. Federal Reserve Bank of Minneapolis.

Christiano, L.J., Eichenbaum, M., Evans, C.L., 1999. Monetary policy shocks: What have we learned and to what end? In: Handbook of Macroeconomics. Elsevier BV, pp. 65-148.

Claessens, S., Habermeier, K., 2013. The interaction of macroeconomic and prudential policy. IMF Executive Summary.

Comon, P., 1994. Independent component analysis, a new concept? Signal Process. 36 (3), 287-314

Committee on the Working of the Monetary System, Radcliffe, C. J. 1959. Report: Committee on the Working of the Monetary System. HM Stationery Office.

Dobb, M., 1975. Theories of Value and Distribution since Adam Smith: Ideology and Economic Theory. Cambridge University Press.

Dow, S., 2017. Central banking in the twenty-first century. Cambridge J. Econ. 41 (6), 1539-1557.

Dutt, A. K., 1990. Growth, distribution and uneven development. Cambridge University Press, Cambridge.

Gambacorta, L., Signoretti, F.M., 2014. Should monetary policy lean against the wind?: an analysis based on a DSGE model with banking. J. Econ. Dyn. Control 43, 146-174

Gourieroux, C., Monfort, A., Renne, J., 2017. Statistical inference for independent component analysis: application to structural VAR models. J. Econ. 196, 111-126.

Hahn, H.F., Matthews, C.O.R., 1964. The theory of economic growth: a survey to structural VAR models. Econ. J. 74 (296), 779-902.

Hyvarinen, A., 1999. Fast and robust fixed-point algorithms for independent component analysis. IEEE Trans. Neural Netw. 10 (3), 626-634.

Hyvärinen, A., Oja, E., 2000. Independent component analysis: algorithms and applications. Neural Netw. 13 (4), 411-430.

IMF, 2015. Monetary policy and financial stability. IMF Policy Paper, August.

Johansen, S., 1991. Estimation and hypothesis testing of cointegration vectors in gaussian vector autoregressive models. Econometrica 1551-1580.

Käfer, B., 2014. The taylor rule and financial stability. a literature review with application for the eurozone. Rev. Econ. 65 (2), 159-192.
Kaldor, N., 1960. The Radcliffe Report. In: The Review of Economics and Statistics, pp. 14-19.

Kaldor, N., 1985. The scourge of monetarism. Oxford University Press, Oxford; New York.

King, R., Plosser, C.I., Stock, J.H., Watson, M.W., 1991. Stochastic trends and economic fluctuations. Am. Econ. Rev. 81 (4), 819-840.

Kociecki, A., Rubaszek, M., Ca'Zorzi, M., 2012. Bayesian Analysis of Recursive SVAR Models with Overidentifying Restrictions. European Central Bank, Working Paper Serier 1492.

Kriesler, P., Lavoie, M., 2007. The new consensus on monetary policy and its post-keynesian critique. Rev. Polit. Econ. 19 (3), 387-404.

Krug, S., 2015. The Interaction between Monetary and Macroprudential Policy: Should Central Banks 'Lean against the Wind' to Foster Macrofinancial Stability? Economics Working Paper, Christian-Albrechts-Universität Kiel.

Lanne, M., Meitz, M., Saikkonen, P., 2017. Identification and estimation of non-gaussian structural vector autoregressions. J. Econ. 196 (2), 288-304.

Lütkepohl, H., 2005. New Introduction to Multiple Time Series Analysis. Springer Science \& Business Media.

Mattesini, F., Becchetti, L., 2009. The stock market and the fed. Appl. Financ. Econ. 19 (2), 99-110.

Moneta, A., Chlaß, N., Entner, D., Hoyer, P., 2011. Causal search in structural vector autoregressive models. In: JMLR Workshops and Conference Proceedings. JMLR, pp. 95-118.

Moneta, A., Entner, D., Hoyer, P.O., Coad, A., 2013. Causal inference by independent component analysis: theory and applications. Oxf. Bull. Econ. Stat. 75 (5), 705-730.

Orphanides, A., 2001. Monetary policy rules based on real-time data. Am. Econ. Rev. 964-985.

Ozkan, F. G., Unsal, D. F., 2014. On the use of monetary and macroprudential policies for small open economies. IMF Working Paper.

Pearl, J., 2009. Causality: Models, Reasoning, and Inference. Cambridge University Press.

Primiceri, G.E., 2005. Time varying structural vector autoregressions and monetary policy. Rev. Econ. Stud. 72 (3), 821-852.

Romer, C., Romer, D., 1989. Does monetary policy matter? a new test in the spirit of friedman and schwartz, 2.

Shapiro, M.D., Blanchard, O.J., Lovell, M.C., 1986. Investment, output, and the cost of capital. Brook. Pap. Econ. Act. 1986 (1), 111-164.

Sharpe, S.A., Suarez, G., 2015. Why isn't investment more sensitive to interest rates: evidence from surveys. Finance and Economics Discussion Series. Federal Reserve Board, Washington D.C.

Shimizu, S., Hoyer, P.O., Hyvärinen, A., Kerminen, A., 2006. A linear non-gaussian acyclic model for causal discovery. J. Mach. Learn. Res. 7, 2003-2030.

Sims, C.A., 1980. Macroeconomics and reality. Econometrica 48 (1), 1-48.

Sims, C.A., 1986. Are forecasting models usable for policy analysis? Fed. Reser. Bank of Minneap. Q. Rev. 2-16.

Smets, F., et al., 2014. Financial stability and monetary policy: how closely interlinked? Int. J. Cent. Bank. 10 (2), 263-300.

Sousa, R.M., 2010. Housing wealth, financial wealth, money demand and policy rule: evidence from the euro area. N. Am. J. Econ. Finance 21 (1), 88-105.

Spirtes, P., Glymour, C.N., Scheines, R., 2000. Causation, prediction, and search. MIT press.

Tamborini, R., 2010. Monetary policy with investment-saving imbalances. Metroeconomica 61 (3), 473-509.

Taylor, J.B., 1993. Discretion versus policy rules in practice. In: Carnegie-Rochester conference series on public policy, Volume 39. Elsevier, pp. 195-214.

Taylor, J.B., 1999. A historical analysis of monetary policy rules. In: Monetary Policy Rules. University of Chicago Press, pp. 319-348.

Taylor, J.B., 2000. Modern macroeconomics at the principles level. Am. Econ. Rev. 90 (2), 90-94.

Taylor, J.B., 2009. Getting off Track: How Government Actions and Interventions Caused, Prolonged, and Worsened the Financial Crisis. Hoover Press.

Taylor, J.B., 2009. How government created the financial crisis. Wall Street J.

Uhlig, H., 2005. What are the effects of monetary policy on output? results from an agnostic identification procedure. J Monet Econ 52 (2), 381-419.

Verona, F., Martins, M.M., Drumond, I., 2014. Financial shocks and optimal monetary policy rules. cef.up Working Paper

Zilberman, R., Tayler, W., et al., 2014. Financial Shocks, Loan Loss Provisions and Macroeconomic Stability. Economics Working Paper Series of Lancaster University, (2014/023). 